\section{ANALYSIS OF ABSENTEEISM-DISEASE OF A COSMETIC INDUSTRY IN SAO PAULO}

${ }^{1}$ KS Arakaki*, ${ }^{2} \mathrm{M}$ Nusbaum*, ${ }^{2} \mathrm{~L}$ Vendramel ${ }^{*}$. ${ }^{1}$ Fundação Getúlio Vargas, São Paulo, Brazil; ${ }^{2}$ Santa Casa de Misericórdia de São Paulo, São Paulo, Brazil

\subsection{6/oemed-2018-ICOHabstracts.390}

Introduction The companies were forced to undergo intense reorganisation movements as a result of the economic crisis installed in early 2015. These movements resulted in important changes in the work environment that influenced the indicators of absenteeism-disease. The study of absenteeism has become an important factor in measuring people management practices and social behaviours. In order to define strategies, help decision making and prevent the increase of these indicators, it is essential to analyse this information.

Methods Descriptive case study on the epidemiological data of medical certificates delivered from January 2015 to December 2016.

Result In 2015, 51.1\% of the certificates were presented by female employees; $39 \%$ aged between 31 and 40 years; $47.6 \%$ of employees between 5 to 10 years of company and $39.4 \%$ of employees with stability in the company. In 2016, $57.2 \%$ of the certificates were submitted by female employees; $47.2 \%$ aged between 31 and 40 years; $41.8 \%$ of employees between 31 to 40 years and $43 \%$ of employees with stability in the company.

Discussion A stratified analysis of absenteeism has proven to be changes in the labour market in the economic crisis installed in 2015 and the groups most susceptible to increased absenteeism. The high prevalence of absenteeism in this employees has shown a need for companies in adopted vocational rehabilitation programs for employees with stability due to occupational diseases.

\section{TANNERIES AND OCCUPATIONAL HEALTH: LITERATURE REVIEW}

${ }^{1}$ Itamar José Costa Resende*, ${ }^{2}$ Silvia Helena Figueiredo Vendramini, ${ }^{2}$ Zaida Aurora Sperli Geraldes Soler. 'OCcupational Physician, JBS, Brazil;' ${ }^{2}$ São José do Rio Preto Medical School's Teacher - FAMERP, Brasil

\subsection{6/oemed-2018-ICOHabstracts.391}

Introduction In Brazil, tanning animal hides is an important economic activity and employ more than 400 thousands workers. There are some occupational riskis in this work process, such as chemical and physical agents, ergonomics, etc. This study aims to make a literature review on tanneries and occupational health.

Methods The review used BIREME - BVS database to find articles searched using keywords 'tannery'. We found 759 documents but 480 were excluded because do not provide full open access. From 279 results, we selected 35 which presented 'occupational exposure' and 'occupational disease' keywords. Only one were in Portuguese language.

Result The productive process can be divided into three major phases: initial (called 'ribeira' in Portuguese), tannery and post-tannery, each with its predominant risks and diseases. The diseases of tanning workers described in the articles were dermatitis (irritatives and atopics) resulting from contact with chemical products used (alkalis, humectants, sulfides, chlorides, whitewash, ammonium salts, chromium III salts and hexavalents, fungicides, dyes), genetic changes linked to chromium use, occupational asthma, and various types of cancer, such as: mouth, pharynx, bladder, kidney, prostate, pancreas, soft tissues sarcomas, and some cases of myeloma.

Discussion The work of tanning is carried out, mainly, in countries with less time of industrialization and/or that are little attentive to the prevention of the workers exposure to the occupational risks to health. Faced with the socio-economic relevance of the sector 'Leathers', it is concluded that the literature is sparse in regards to the tanneries and occupational health issue.

\section{COMPUTER VISION SYNDROME AND VISUAL FUNCTION IN COMPUTER USERS WORKERS IN SÃO PAULO: PREVALENCE AND ASSOCIATED FACTORS}

Eduardo C Sá*, C Martinez Maria, M Fischer Frida. Faculdade de Saúde Pública da Universidade de São Paulo, São Paulo, Brazil

\subsection{6/oemed-2018-ICOHabstracts.392}

Introduction The American Optometric Association (AOA) defines the Computer Vision Syndrome (CVS) as a syndrome resulting from eye and vision problems, related to computer use at work or do not. The symptoms occur because the visual demands of the task exceed the visual capabilities of the individual to perform comfortably (SEGUÍ, et al., 2015). The objective of this study was to analyse the symptoms of CVS and factors associated with visual function among computer users in an administrative function of a public university hospital of São Paulo $(n=303)$.

Methods A quantitative cross-sectional observational study was carried out between 2014 and 2015, in which the workers underwent a clinical ophthalmologic examination and answered a questionnaire. For the Visual Function Questionnaire (VFQ-25) a Kolmogorov-Smirnov test was performed to characterise the study population, and the ANOVA, MannWhitney and Kruskal-Wallis tests were used to analyse the associated factors. A multiple linear regression model was created, using stepwise forward, with variables that presented significance levels with $p<0.20$. They remained in the final model, the variables that presented descriptive levels $\mathrm{p}<0.05$.

Result The most frequent symptoms were 'tiredness at work' (47.9\%), 'weight in the eyeat work' (38.3\%) and 'tiredness at home' (36.3\%). It was found an association between age (OR $0.188 ; 95 \% \mathrm{CI}:-0.276$ to -0.161$)$ and effort at work (OR 0.656 ; CI -0.928 to -0.383 ) with visual function. In the work effort, the items that appeared as the main sources of stress were: 'interruptions at work' (3.7\%),'overtime work' (3.6\%) and increased demand (3.6\%).

Discussion In this study, the importance of work organisation and the psychosocial factors at work associated to the presence of CVS and the alterations of the visual function in computer users workers were observed. Suggestions include improvement of the work organisation, as well as periodic eye exams for this category of workers. 